nerships, is strongly concentrated on Russia, other postSoviet countries, and neighboring countries.

At the same time, Kazakhstan's universities are aware of their comparative advantage in higher education provision among Central Asian countries. The respondents in our study mentioned that the recruitment of foreign students should not exclusively focus on European countries. Instead, more attention should be paid to attract more students from neighboring countries. Whether this institutional demand fits into the national strategy, and thus gains support from the government, remains to be seen.

\section{The Language Gap}

Language can also create a sense of distance: poor proficiency in foreign languages, particularly in English, is reported to be another major barrier to internationalization. Participants in our study frequently cite this as an obstacle at various levels: for instance, student and faculty mobility, research collaboration, and international office operations. This also extends to the lack of availability of Englishlanguage programs in Kazakhstani institutions, as well as qualified teaching staff. In comparison, respondents who report excelling in foreign languages see this as a strength for developing international partnerships. The rectors of those institutions lagging behind in foreign languages say that they are investing in improving language proficiency as an important step toward internationalization.

\section{Open Dialogue and Cooperation}

The above factors certainly do not cover every aspect of the process of internationalization of higher education in Kazakhstan, and further research in our project will look into these. Even so, one can see key areas of potential challenges that the Kazakhstani government and higher education institutions face. In the first place, there is a wide gap between Kazakhstan and more developed countries in terms of internationalization. Secondly, there is also a gap developing within the country between institutions, particularly between metropolitan and regional ones. The Kazakhstani government has demonstrated its ambition to internationalize its higher education institutions, as evidenced by its policies and financial support. Higher education institutions are also actively participating in the process. However, there needs to be a more open dialogue and closer cooperation between the government and institutions to align their visions and construct effective support mechanisms, in order to make further progress in internationalization.

\section{Internationalization of} Japanese Universities: Learning from the CAMPUS Asia Experience

\section{MIKI HorIE}

Miki Horie, PhD is associate professor at Ritsumeikan International, Ritsumeikan University, Japan. She was a visiting scholar at CHEI in Milan in the fall of 2013. E-mail: mhorie@fc.ritsumei.ac.jp.

$\mathrm{W}$ hat has internationalization brought to Japanese higher education institutions? Japanese universities experience various reforms and self-improvement processes as responses to the internationalization policies initiated by the Japanese government since I980s. The major focus of the government before 2000 was to increase the number of international students, and from then it started to undertake multidimensional approaches to internationalization, including promotion of outbound and multilateral mobility, development of English-taught programs, and collective efforts for international student recruitment. Universities responded to requirements and expectations in various ways within the frameworks that come with the government's financial support. Through such efforts, Japanese universities have accumulated collective experience and knowledge.

One significant outcome is the increased awareness of the need to apply alternative pedagogical models—such as, experiential, active, and collaborative learning schemeswhich serve students more efficiently and effectively in cross-cultural learning environments. One of the examples is the policy called CAMPUS Asia, or "Collective Action for Mobility Program of University Students in Asia," which challenges Japanese universities to develop joint programs with Chinese and Korean counterparts for mutual understanding. This is the first joint governmental initiative between Japan, China, and Korea, to educate their youth together. The three governments jointly selected ten project proposals-in other words, ten consortia of Japanese, Chinese, and Korean universities—as grant recipients.

\section{The "East Asian Leaders" Program}

After one year of implementation, the government committee responsible for the interim evaluation of CAMPUS Asia gave the highest grade to one program among the Io selected, the "East Asian Leaders" program operated by Ritsumeikan University (Japan), Guangdong University of Foreign Studies (China), and Dongseo University (Korea). Besides the interim evaluation, another sign of success lies in the fact that the participants of the program have started 
to identify themselves as change-makers and peacemakers of the region and the world.

The first unique feature of this program is its strong emphasis on a cross-cultural peer-learning environment. The participants of the program, Io from each institution, 30 in total, form a cohort group and spend 6 trimesters together as a part of 4-year BA program. They spend the first term in China, move to Japan for the second term, then to Korea for the third term, and repeat the same itinerary in the second year. They live and learn together, while some intercultural training is provided to them. For example, while sharing a small Japanese traditional house in Kyoto, they naturally started setting up common rules for peaceful room-sharing experiences beyond cultural differences in everyday details. Such an intensive setting motivated students to learn to communicate in constructive ways, instead of just complaining or blaming someone, and accept various ideas.

Second, students are expected to learn Japanese, Chinese, and Korean languages at the same time. Japanese and Korean students learn Chinese in China, and Chinese students help them learning. This host-guest relationship is flipped in Japan or in Korea. Everyone is a language learner equally, and this setting also fosters everyone to be empathetic peer teachers of the languages. English is not used in this program.

\section{Students are expected to learn Japa- nese, Chinese, and Korean languages at the same time; and English is not used in this program.}

Third, its core subjects are East Asian humanity studies from historic, cultural, and political perspectives. Such knowledge, in addition to the personal skills that they obtain through daily life, creates a safer and less threatening foundation to discuss existing political conflicts among the three countries. In the second term, they discuss differences in history textbooks of each country, focusing on a description of the Japanese invasion to Korea and China. Korean and Chinese textbooks illustrate various incidents around the time of Japanese invasion, but Japanese textbooks do not cover them much. This usually causes a knowledge gap and becomes a fundamental source of political dispute. The program helps students to obtain skills and attitudes to overcome emotional difficulties to discuss such sensitive issues and to reach a higher level of constructiveness in conversation.
Fourth, this program gives students the "second chance" and, thus, an extra awareness to their personal development. After finishing the first year, they go to China, Japan, and Korea again. Being for the first time in a new cultural environment is always challenging but in the second round students with their newly developed intercultural skills and attitudes try out something that they failed to handle a year ago and so become aware of what skills they gained in the past year.

\section{Challenges for Further Implementation}

The above-described case provides some insights for further implementation of cross-cultural joint programs. The new 20I4 Japanese government grant for comprehensive internationalization encourages institutions to create joint degree programs with overseas partners, which is a big new challenge for Japanese universities. Operating quality programs requires teaching and coordinating staff who fully understand the pedagogical principles and are capable of facilitating such learning inside and outside the classroom. The director on the Chinese side in the East Asian Leaders program pointed out the importance of understanding the uniqueness of group dynamics among the students. The administration team on the Japan side says that it is crucial to pay very careful attention to group dynamics of the students and to provide them with various intercultural group communication trainings and consultations. Many of the key staff of the three institutions speak more than two of the languages. This successful model is supported by a group of teaching and administrating staff members, who are not necessarily experts of cross-cultural peer learning at the beginning but are open and willing to accept and understand the unique learning process in this context. One challenge for many Japanese universities is to find such individuals at a practical level, both from the academic and administrative side, to form a team that actually functions.

Another challenge is an examination of various measurements of learning outcomes, to illustrate the uniqueness of student development in such programs. Many different measurement tools such as the "Intercultural Development Inventory" are available and useful to understand certain aspects of students' learning. However, we have to figure out at what level such schemes developed outside of East Asia are applicable to the East Asian students and how we can find a suitable combination of different schemes to properly communicate the outcome and the students' characteristics to the public and to the students themselves. Moreover, there is limited knowledge in Japan about the personal and social expectations of the students of those countries and how such preconceptions diversify or not the students' learning outcomes. Closer examination of such aspects helps to create programs that are more ben- 
eficial to each individual and thus enhances the impact of the internationalization of Japanese higher education.

\section{Consolidating ERASMUS Mobility in Spain During the Economic Crisis}

\section{Adriana Pérez Encinas}

Adriana Pérez Encinas is assistant lecturer and researcher in higher education at the Faculty of Business and Economics, Universidad Autónoma de Madrid, Spain. E-mail: adriana.perez.encinas@uam.es.

$\mathrm{T}$ he ERASMUS+ program of the European Commission, which is funded during the period 20I4-2020 and includes education and training as well as youth and sport activities, is motivating thousands of European students to undertake part of their studies abroad. It has received a significant budget increase-40 percent more, in fact-over what was allocated for the previous ERASMUS program, which over the past 25 years has enabled more than 3 million students to study abroad as part of their home degree. The crisis in Spain is leading thousands of university students to decide to carve out a better future for themselves by carrying out internships, part of their studies, their whole degree in other European countries, or even on other continents. Despite the fact that the length of the ERASMUS grant has been reduced to one semester and that many families cannot easily afford this economic burden, ERASMUS mobility is being consolidated as part of the Spanish university curriculum.

\section{ERASMUS Mobility WITHIN the ACAdemic Curriculum}

From the students' perspective, there are four main reasons for taking part in the program during their studies: to enhance their academic program, to find a job after their studies, to improve their foreign language competences, and to acquire an international perspective and experience. All of these are related and help young graduates to enter the labor market. A study carried out among 240 outgoing students at the Universidad Autónoma de Madrid (with a response rate of 46 percent) found that 89 percent of the students surveyed assumed that having taken part in a mobility program would help them find a job in the future.

In many European universities, students are encouraged to complete part of their studies abroad. Under ERASMUS, students are exempt from paying fees at the host university and the credits they earn are recognized through a learning agreement signed by the student, the home university, and the host institution(s). The European Commission has set itself a target of 20 percent of mobile students by 2020 .

In Spain, as in other countries, ERASMUS mobility is not a "compulsory period abroad" in the academic curricula of most higher education institutions. Mobility windows as part of the curriculum are accessed predominantly on a voluntary basis and as a matter of student initiative, facilitated by the institution. Nevertheless, many students are keen to apply for a mobility program to enrich their CVs and to develop competences that will distinguish them from others.

\section{ERASMUS Mobility AND the EConomic Situation}

The latest statistics released by the European Commission on ERASMUS student mobility 20I2-2013 reveal that a new record has been achieved, with the program becoming more popular than ever. Moreover, this increasing trend in mobility numbers is seen both for study and internship

\section{More than 25 percent of Spanish are un- employed and 53.5 percent of Spaniards under age 25 have never worked.}

purposes, with internships now part of the program. Spain has maintained its leading position as the country that both receives and sends the highest number of ERASMUS students. In the academic year 20I2-20I3, 39,249 Spanish students joined the ERASMUS program. Although this is I percent less than the previous year, the data confirm that mobility is being consolidated in Spanish higher education institutions and is an implicit but important part of their curricula, notwithstanding the economic crisis.

Spain appears to be a country that attracts international talent to its universities, companies and institutions, as well as a country full of students keen to gain international experience and improve their CVs. The main concern now is not the students' desire to go abroad and explore new horizons, but the insufficient budget they receive to cover their living costs in the host country. This means that many Spanish families have to make significant financial efforts to cover the cost of the mobility period, in order to invest in their children's future.

Additionally, unemployment is one of the main worries of Spain's youth. The population of Spain is around 47 million inhabitants; but more than 25 percent are unemployed; 